\title{
Effects of pre-transplant azithromycin administration on kidney graft function: study protocol for a double-blind randomized clinical trial
}

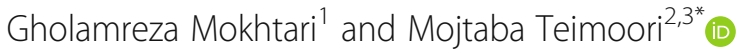

\begin{abstract}
Background: Kidney transplantation is the best strategy for the management of end-stage renal disease; however, the outcomes need to improve further. Macrolides show antimicrobial and anti-inflammatory properties in chronic diseases and intraoperatively, and can accumulate in tissues for extended periods. Therefore, theoretically, when administered to a donor and because of accumulation in the donor kidney, macrolides can cause graft immunomodulation and improve kidney transplantation outcomes.

Methods: This study is a single-center, randomized clinical trial. A total of 60 kidney donors will be randomly allocated to the azithromycin or placebo group and treated with a single dose $(1 \mathrm{~g})$ of azithromycin or placebo, respectively, 1 day before surgery. Recruitment commenced in September 2016 and is expected to be completed by March 2018. The primary outcome is kidney graft function. The secondary outcomes include rejection rate, urinary tract infections in graft recipients, pain and systemic inflammatory response syndrome in live donors, and complications in both donors and recipients. Outcomes will be evaluated at baseline and every day in the first week after transplantation, as well as at 1 and 3 months post transplantation. Adverse reactions will be documented. If the efficacy of azithromycin in reducing adverse outcomes is confirmed, it would serve as an easy to use, economic intervention able to lower post-transplantation risks.
\end{abstract}

Discussion: Short and mid-term analyses of blood and urine samples as well as immunological assays will facilitate a more in-depth analysis of the effects of azithromycin on transplantation outcomes.

Trial registration: Iranian Clinical Trial Registry, IRCT201606141853N11, registered on September 5, 2016.

Keywords: Azithromycin, Kidney transplantation, Immunomodulation, Graft rejection, Transplant recipients

\section{Background}

The incidence and prevalence of end-stage renal disease necessitating dialysis or transplantation has not changed in the past few decades, with these even increasing in developing countries, wherein healthcare needs to be improved in line with the burden of disease $[1,2]$. Compared to dialysis, a kidney transplant affords significantly better survival and quality of life to end-stage renal disease patients, making transplantation one of the most cost-effective surgeries [3].

\footnotetext{
* Correspondence: mojtaba_teimoori@yahoo.com

¿Urology Department, Guilan University of Medical Sciences, Rasht, Guilan, Iran

${ }^{3}$ Urology Research Center, Razi Hospital, Sardar jangle St, Rasht, Guilan, Iran Full list of author information is available at the end of the article
}

Therefore, preventing graft loss after kidney transplantation is crucial.

The immunomodulatory properties of antibiotics such as macrolides have been studied and reported [4-6]. Azithromycin is a member of the macrolide (azalide) family and its blood serum concentration can be $\geq 100$-fold that in body tissues, especially in leukocytes [7, 8]. It can accumulate in body tissues for up to a month even following administration of a single dose [9]. Therefore, azithromycin administered to kidney donors may persist in transplanted kidney cells, especially in the immune cells of the grafted kidney.

Mammalian target of rapamycin (mTOR) is a cytoplasmic protein that plays a key role in the activation of immune 
cells following foreign stimulation and is now believed to be a major immune system controller [10], making rapamycin one of the most important drugs in transplantation [11]. Ratzinger et al. [11] showed that azithromycin exerts an immunomodulatory effect on CD4 (+) T-cells by preventing mTOR activity. Thus, administration of azithromycin prior to a transplant can result in prolonged drug accumulation in the kidney and modulate inflammatory processes locally.

The immunomodulatory influence of macrolides has been shown to lower the expression of inflammatory genes [12] and affect the production and efficacy of many pro-inflammatory cytokines such as interleukin (IL)-1, IL-6, IL-8 and tumor necrosis factor [13, 14]. Chemoattractant and inflammatory molecules have been reported to be crucial determinants in kidney rejection $[15,16]$. Azithromycin can limit the signaling of chemoattractants such as IL-8 and reduce the production of inflammatory molecules such as granulocyte macrophage colony-stimulating factor, which contribute to neutrophil attraction to inflamed organs. Thus, the anti-inflammatory action of macrolides can prevent leukocyte infiltration into the transplanted kidney.

To our knowledge, no published study has evaluated the effects of macrolide administration in kidney donors on outcomes in kidney recipients. Azithromycin administration to cadaveric or live donors can theoretically result in drug accumulation in the donated kidney, where it exerts an immunomodulatory effect and can reduce preoperative adverse outcomes such as rejection. The effects of azithromycin in other organ transplantations have been previously shown. Azithromycin therapy following keratoplasty yielded results similar to those achieved with topical dexamethasone, without the risk of adverse effects commonly associated with steroidal drugs and enhanced graft survival in rats [17]. A study found that azithromycin promoted the survival of high-risk corneal allografts, apparently without modulating the immune system [18]. Iwamoto et al. [19] reported that azithromycin, with its immunomodulatory properties, is a potential prophylactic drug for the lethal graft-versus-host disease.

In this study, we will assess the safety and efficacy of azithromycin administration to kidney donors and its effects on both donor and recipient outcomes.

\section{Methods}

\section{Overview of the study design}

We designed a double-blind randomized clinical trial (RCT). The interventions will be performed at an academic institution, The Affiliated Hospital of the Guilan University of Medical Science, Guilan, Iran.

\section{RCT flow chart}

Prior to inclusion, all participants will be screened at the Urology Research Center and will then be randomized into the azithromycin or placebo group. Following randomization, the participants will receive $1 \mathrm{~g}$ of azithromycin or placebo 1 day before surgery. The outcome will be evaluated by investigators blinded to the group randomization, during the study. Adverse events will be documented for safety assessment.

The study protocol has been reviewed and approved by local institutional review boards and ethics committees. The trial adheres to the principles of the CONSORT (Fig. 1), the Standard Protocol Items: Recommendations for Interventional Trials (SPIRIT) (Fig. 2) (checklist as an Additional file 1), and the Declaration of Helsinki (sixth revision, 2008).

\section{Participants}

All procedures will be performed at Razi Hospital University Medical Center. All kidney donors considered for randomization would be informed of the study protocol. The standard preoperative screening of donors will include an examination by a nephrologist, a transplant surgeon, and an anesthetist. Renal ultrasonography, magnetic resonance angiography, or digital subtraction angiography will be performed to evaluate the vascular anatomy of the kidneys. If both kidneys are suitable for transplantation, the right kidney would be preferred. All recipients would undergo follow-up examinations every day for a week after surgery, and at 1 and 3 months post transplantation.

\section{Sample size}

The sample size was determined based on the fact that 36 subjects per group would appear adequate to provide estimates precise enough to meet our aim (pilot study) [20].

\section{Inclusion criteria}

1. Live or cadaveric donor.

2. Informed consent form signed by the live donor or consent provided by the guardian or next-of-kin for a deceased donor.

\section{Exclusion criteria}

1. Known allergies, including allergies caused by azithromycin.

2. Severe heart, liver, or renal dysfunction or hematological, respiratory, cardiovascular, psychiatric, or metabolic disease within a 6-week period before transplantation.

3. Use of hormonal or other medication, including macrolides.

4. Concurrent participation in other clinical trials. 


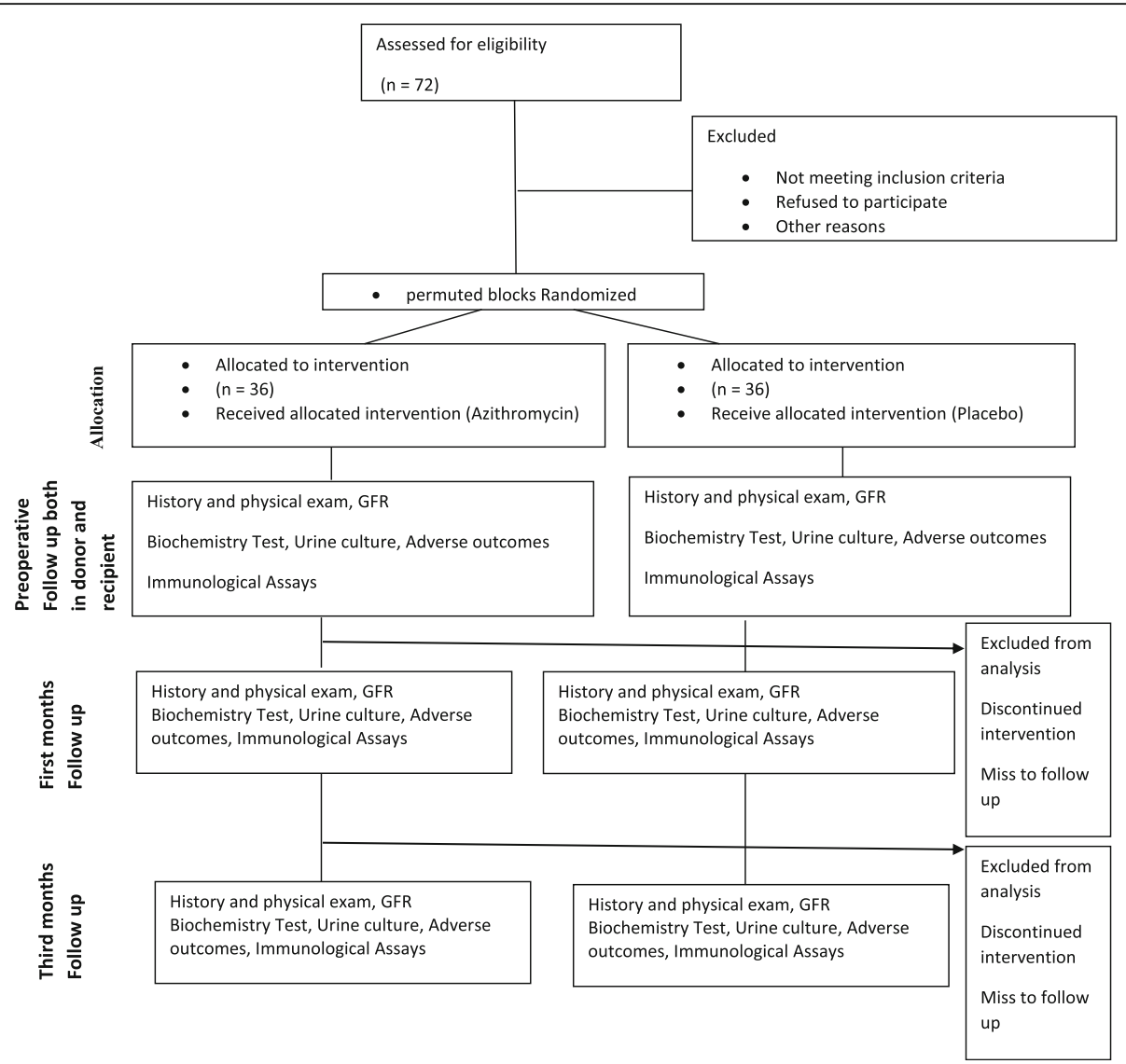

Fig. 1 Consolidated Standards of Reporting Trials (CONSORT) diagram showing the flow of participants through each stage of a randomized trial

\section{Randomization}

Participants will be randomly assigned to either the azithromycin or placebo group by using the method of random permuted blocks [21].

\section{Blinding}

This is a double-blind trial; therefore, both the patients and the clinical practitioners will be blinded at all stages of the RCT. Furthermore, to prevent potential biases, other researchers, including data collectors and statisticians, will also be blinded to the trial.

\section{Interventions}

Live donors in the azithromycin group will receive $1 \mathrm{~g}$ of azithromycin (four capsules of $250 \mathrm{mg}$ ) orally 1 day prior to surgery. Capsules will be opened, and the powder will be mixed with $10-15 \mathrm{~mL}$ of sterile water and immediately administered via a gastric tube in the case of deceased donors. The tube will be pre-flushed with $30 \mathrm{~mL}$ of sterile water; after administration, the tube will be flushed again with $30 \mathrm{~mL}$ of sterile water and clamped. The participants in the control group will receive a placebo. To ensure compliance, all live donors will ingest the capsules in the presence of a physician [22]. Possible side effects due to the azithromycin treatment will be monitored; to our knowledge, there are no contraindications for administering azithromycin through enteral feeding tubes [23]. In cases of serious side effects, the trial will be ended and treated.

\section{Immunotherapy protocols}

Maintenance immunosuppression therapy in most recipients will consist mainly of cyclosporine. The majority of patients will also receive mycophenolate mofetil and prednisolone, except for those who experience side effects. All medical regimens will be recorded during hospital visits.

\section{Patient follow-up}

Patients will be followed for 3 months after treatment. Clinicians will examine the patients every day for a week after surgery, and again at 1 and 3 months.

\section{Outcome measures}

Primary outcome

The primary outcome will be the kidney graft function (evaluated using the glomerular filtration rate). 


\begin{tabular}{|c|c|c|c|c|c|c|c|c|c|c|c|c|}
\hline & \multicolumn{12}{|c|}{ STUDY PERIOD } \\
\hline & \multirow{2}{*}{$\begin{array}{c}\text { Enrolment } \\
\text { Before } \\
\text { Transplant } \\
\end{array}$} & \multirow{2}{*}{$\begin{array}{c}\text { Allocation } \\
0\end{array}$} & \multicolumn{10}{|c|}{ Post-allocation days } \\
\hline TIMEPOINT & & & 1 & 2 & 3 & 4 & 5 & 6 & 7 & 31 & 31 & 91 \\
\hline ENROLMENT: & & & & & & & & & & & & \\
\hline Eligibility screen & $\mathrm{X}$ & & & & & & & & & & & \\
\hline $\begin{array}{r}\text { Informed } \\
\text { consent }\end{array}$ & $\mathrm{X}$ & & & & & & & & & & & \\
\hline $\begin{array}{r}\text { Demographics } \\
\text { and Medical } \\
\text { History }\end{array}$ & $\mathrm{X}$ & & & & & & & & & & & \\
\hline Medication & $\mathrm{X}$ & & $\mathrm{X}$ & $\mathrm{X}$ & $\mathrm{X}$ & $\mathrm{X}$ & $\mathrm{X}$ & $\mathrm{X}$ & $\mathrm{X}$ & $\mathrm{X}$ & $\mathrm{X}$ & $\mathrm{X}$ \\
\hline Physical Exam & $X$ & & $\mathrm{X}$ & $X$ & $\mathrm{X}$ & $\mathrm{X}$ & $\mathrm{X}$ & $X$ & $\mathrm{X}$ & $\mathrm{X}$ & $X$ & $\mathrm{X}$ \\
\hline $\begin{array}{r}\text { HLA Mismatch } \\
\text { Degree }\end{array}$ & $\mathrm{X}$ & & & & & & & & & & & \\
\hline Allocation & & $\mathrm{X}$ & & & & & & & & & & \\
\hline GFR estimation & $\mathrm{X}$ & & $\mathrm{X}$ & $\mathrm{X}$ & $\mathrm{X}$ & $\mathrm{X}$ & $\mathrm{X}$ & $\mathrm{X}$ & $\mathrm{X}$ & $\mathrm{X}$ & $X$ & $\mathrm{X}$ \\
\hline $\begin{array}{r}\text { Complete Blood } \\
\text { cell Count }\end{array}$ & $\mathrm{X}$ & & $X$ & $\mathrm{X}$ & $\mathrm{X}$ & $\mathrm{X}$ & $\mathrm{X}$ & $\mathrm{X}$ & $\mathrm{X}$ & $\mathrm{X}$ & $\mathrm{X}$ & $\mathrm{X}$ \\
\hline CRP & $\mathrm{X}$ & & $\mathrm{X}$ & $\mathrm{X}$ & $\mathrm{X}$ & $\mathrm{X}$ & $\mathrm{X}$ & $\mathrm{X}$ & $\mathrm{X}$ & $\mathrm{X}$ & $\mathrm{X}$ & $\mathrm{X}$ \\
\hline ESR & $\mathrm{X}$ & & $\mathrm{X}$ & $\mathrm{X}$ & $\mathrm{X}$ & $\mathrm{X}$ & $\mathrm{X}$ & $\mathrm{X}$ & $\mathrm{X}$ & $\mathrm{X}$ & $X$ & $\mathrm{X}$ \\
\hline Interleukin 2 & $\mathrm{X}$ & & $\mathrm{X}$ & $\mathrm{X}$ & $\mathrm{X}$ & $X$ & $X$ & $X$ & $\mathrm{X}$ & $X$ & $X$ & $X$ \\
\hline $\begin{array}{r}\text { Pain in Alive } \\
\text { Donor }\end{array}$ & $X$ & & $X$ & $X$ & $X$ & $X$ & $X$ & $X$ & $X$ & & & \\
\hline $\begin{array}{r}\text { Severe } \\
\text { Inflammatory } \\
\text { Response in } \\
\text { alive donor }\end{array}$ & & & $X$ & $X$ & $X$ & $X$ & $X$ & $X$ & $x$ & & & \\
\hline $\begin{array}{r}\text { Liver function } \\
\text { Test }\end{array}$ & $X$ & & $X$ & $X$ & $X$ & $X$ & $X$ & $X$ & $X$ & $X$ & $X$ & $X$ \\
\hline $\begin{array}{c}\text { Urinalysis and } \\
\text { urine culture }\end{array}$ & $X$ & & $X$ & $X$ & $X$ & $X$ & $X$ & $X$ & $X$ & $X$ & $X$ & $X$ \\
\hline $\begin{array}{r}\text { Surgery } \\
\text { Complication }\end{array}$ & & & $X$ & $X$ & $X$ & $X$ & $X$ & $X$ & $X$ & $X$ & $X$ & $X$ \\
\hline $\begin{array}{r}\text { Drug Adverse } \\
\text { Event }\end{array}$ & & & $X$ & $X$ & $X$ & $X$ & $X$ & $X$ & $x$ & $X$ & $X$ & $X$ \\
\hline
\end{tabular}

Fig. 2 Standard Protocol Items: Recommendations for Interventional Trials (SPIRIT)

\section{Secondary outcomes}

Other studies have reported that prophylaxis with macrolides can decrease systemic inflammatory response syndrome [24, 25]. Chow et al. [24] reported that clarithromycin therapy reduced febrile response, tachycardia, tachypnea, and the strength and length of postoperative pain, and suppressed an increase in monocyte counts, concluding that macrolide treatment can yield improved clinical outcomes. Therefore, the secondary outcomes in our RCT will be the rejection rate, pain and systemic inflammatory response syndrome in donors, and complications and inflammatory responses in both donors and recipients.

Theoretically, azithromycin accumulated in the grafted kidney can decrease the rate of urinary tract infections (UTIs) after transplantation, because of the antimicrobial effect of azalide drugs. Azithromycin has been shown to inhibit UTIs caused by Pseudomonas aeruginosa, which are mainly catheter-associated UTIs [26, 27]; therefore, another secondary outcome in the study will be the incidence of UTIs in recipients.

\section{Outcome evaluation schedule}

Outcomes will be assessed at baseline and at 1 and 3 months post transplantation. The patients will undergo routine blood tests, liver function tests, and kidney function tests. The overview of the outcome evaluation schedule is shown in Fig. 1.

\section{Assessment of adverse events}

According to previous RCTs, azithromycin administration may cause several types of adverse events, including hearing loss, cardiac arrhythmia, nausea, and vomiting [28]. Adverse events will be carefully recorded in case report forms.

\section{Statistical analysis}

We will use standard descriptive statistics to assess baseline clinical and laboratory data at enrollment. Subsequently, we will compare creatinine levels at the end of each study period by using mixed models for repeated measures. Fixed factors will include the degree of human leukocyte antigen 
mismatch, age, sex, etiology of and baseline comorbidity, medication (azithromycin or placebo), and baseline laboratory test parameters (inflammatory and non-inflammatory markers). Complications, UTIs, and other outcomes will be similarly evaluated. Nominal data will be compared using the Student's $T$ test and categorical data will be compared using the $\chi^{2}$ test. Patients who drop out during the study period will be analyzed until the last hospital visit at which data are collected. $P<0.05$ will be considered as a significant level. All data will be analyzed using SPSS software Version 20.

\section{Discussion}

The strength of this trial is that it is a well-designed, novel, double-blind RCT. It will provide evidence of the effect of azithromycin on kidney transplantation outcomes. The secondary objectives will allow us to examine the effect of azithromycin on UTI rates in recipients and pain and inflammatory responses in both donor and recipients. Further, short and mid-term analyses of blood and urine samples as well as immunological assays will enable a more in-depth analysis of the effects of azithromycin on transplantation outcomes. On the other hand, the limitation of this trial is that the importance of graft function may be overestimated due to the evaluation of graft function for 90 days because of short-term drug influences.

\section{Trial status}

Patient enrollment began in September 2016 and is still ongoing. The study is expected to conclude in March 2018. Final results from this RCT are expected in the second quarter of 2018. The results will be published in national and international peer-reviewed journals.

\section{Additional file}

Additional file 1: SPIRIT 2013 Checklist: Recommended items to address in a clinical trial protocol and related documents*. (DOCX $52 \mathrm{~kb}$ )

\section{Abbreviations}

IL: interleukin; mTOR: mammalian target of rapamycin; RCT: randomized controlled trial; UTI: urinary tract infection

\section{Acknowledgements}

The authors are grateful to Samane Esmaili for help with the paperwork. In addition, we wish to thank Dr. Aghajan Zade and Dr. Monfared who made valuable suggestions and contributed to the preparation of the manuscript

\section{Funding}

This trial was financially supported by funds from the Urology Research Center, Guilan University of Medical Science, Rasht, Iran (Grant number 707/ 13.4.1395). The funder had no role in study design, collection, analysis and interpretation of data, or writing of the manuscript.

\section{Availability of data and materials}

The datasets will generate and analyses during the current study will available in the Mendely repository [https://doi.org/10.17632/3z7h34dxgp.1].

\section{Authors' contributions}

MT wrote the trial protocol, and GM reviewed the protocol and aided in the study design. Both authors wrote the original draft, and read and approved the final manuscript.

Ethics approval and consent to participate

All participants who meet the inclusion criteria will be asked to sign the informed consent form. The study protocol has already been approved by the Guilan Medical University Ethics Review Committee (approval identifier: IR. GUMS.REC1395.105).

Consent for publication

Not applicable.

Competing interests

The authors declare that they have no competing interests.

\section{Publisher's Note}

Springer Nature remains neutral with regard to jurisdictional claims in published maps and institutional affiliations.

\section{Author details}

${ }^{1}$ Transplant surgeon, Urology Research Center, Razi Hospital, Guilan University of Medical Sciences, Rasht, Guilan, Iran. ${ }^{2}$ Urology Department, Guilan University of Medical Sciences, Rasht, Guilan, Iran. ${ }^{3}$ Urology Research Center, Razi Hospital, Sardar jangle St, Rasht, Guilan, Iran.

Received: 8 February 2018 Accepted: 14 June 2018

Published online: 28 June 2018

\section{References}

1. Wang V, Vilme H, Maciejewski ML, Boulware LE. The economic burden of chronic kidney disease and end-stage renal disease. Semin Nephrol. 2016;36:319-30.

2. Wetmore JB, Collins AJ. Global challenges posed by the growth of endstage renal disease. Ren Replace Ther. 2016;2:15.

3. Matas AJ, Smith JM, Skeans MA, Thompson B, Gustafson SK, Stewart DE, et al. OPTN/SRTR 2013 annual data report: kidney. Am J Transplant. 2015; 15(Suppl 2):1-34.

4. Kirst HA. New macrolides: expanded horizons for an old class of antibiotics. J Antimicrob Chemother. 1991;28:787-90.

5. Kirst HA, Sides GD. New directions for macrolide antibiotics: pharmacokinetics and clinical efficacy. Antimicrob Agents Chemother. 1989;33:1419-22.

6. Villa ML, Valenti F, Scaglione F, Falchi M, Fraschini F. In-vivo and in-vitro interference of antibiotics with antigen-specific antibody responses: effect of josamycin. J Antimicrob Chemother. 1989:24:765-74.

7. Wildfeuer $\mathrm{A}$, Laufen $\mathrm{H}$, Zimmermann T. Uptake of azithromycin by various cells and its intracellular activity under in vivo conditions. Antimicrob Agents Chemother. 1996;40:75-9.

8. Solidoro P, Braido F, Boffini M, Corsico AG. New life for macrolides. Minerva Med. 2013;104:7-14.

9. Foulds $G$, Shepard RM, Johnson RB. The pharmacokinetics of azithromycin in human serum and tissues. J Antimicrob Chemother. 1990;25(Suppl A):73-82.

10. Stallone G, Infante B, Di Lorenzo A, Rascio F, Zaza G, Grandaliano G. mTOR inhibitors effects on regulatory $T$ cells and on dendritic cells. J Transl Med. 2016:14:152.

11. Ratzinger F, Haslacher H, Poeppl W, Hoermann G, Kovarik JJ, Jutz S, et al. Azithromycin suppresses CD4(+) T-cell activation by direct modulation of mTOR activity. Sci Rep. 2014;4:7438.

12. Cory TJ, Birket SE, Murphy BS, Hayes D Jr, Anstead MI, Kanga JF, et al. Impact of azithromycin treatment on macrophage gene expression in subjects with cystic fibrosis. J Cyst Fibros. 2014;13:164-71.

13. Scaglione F, Rossoni G. Comparative anti-inflammatory effects of roxithromycin, azithromycin and clarithromycin. J Antimicrob Chemother. 1998:41(Suppl B):47-50.

14. Sugiyama K, Shirai R, Mukae H, Ishimoto H, Nagata T, Sakamoto N, et al. Differing effects of clarithromycin and azithromycin on cytokine production by murine dendritic cells. Clin Exp Immunol. 2007;147:540-6. 
15. Strieter RM, Kasahara K, Allen RM, Standiford TJ, Rolfe MW, Becker FS, et al. Cytokine-induced neutrophil-derived interleukin-8. Am J Pathol. 1992; 141:397-407.

16. Shinkai M, Foster GH, Rubin BK. Macrolide antibiotics modulate ERK phosphorylation and IL-8 and GM-CSF production by human bronchial epithelial cells. Am J Physiol Lung Cell Mol Physiol. 2006;290:L75-85.

17. Wacker K, Denker S, Hildebrand A, Eberwein P, Reinhard T, Schwartzkopff J. Short-term azithromycin treatment promotes cornea allograft survival in the rat. PLoS One. 2013;8:e82687.

18. Medina CA, Rowe AM, Yun H, Knickelbein JE, Lathrop KL, Hendricks RL. Azithromycin (AZM) treatment increases survival of high-risk corneal allotransplants. Cornea. 2013;32:658-66.

19. Imamoto S, Azuma E, Kumamoto T, Hirayama M, Yoshida T, Ito M, et al. Efficacy of azithromycin in preventing lethal graft-versus-host disease. Clin Exp Immunol. 2013:171:338-45.

20. Hertzog MA. Considerations in determining sample size for pilot studies. Res Nurs Health. 2008;31:180-91.

21. Dallal GE. Randomization.com. 2016

22. Williams NT. Medication administration through enteral feeding tubes. Am J Health Syst Pharm. 2008:65:2347-57.

23. Wohlt PD, Zheng L, Gunderson S, Balzar SA, Johnson BD, Fish JT. Recommendations for the use of medications with continuous enteral nutrition. Am J Health Syst Pharm. 2009;66:1458-67.

24. Chow LW, Yuen KY, Woo PC, Wei WI. Clarithromycin attenuates mastectomy-induced acute inflammatory response. Clin Diagn Lab Immunol. 2000;7:925-31.

25. Eremenko AA, Chernova EV, Vinnitskii LI, Buniatian KA, Inviiaeva EV, Bogomolova NS, et al. Effect of clarithromycin on the systemic inflammatory response syndrome severity in patients after myocardial revascularization surgery. Anesteziol Reanimatol. 2012;3:67-71.

26. Xu ZG, Gao Y, He JG, Xu WF, Jiang M, Jin HS. Effects of azithromycin on Pseudomonas aeruginosa isolates from catheter-associated urinary tract infection. Exp Ther Med. 2015:9:569-72.

27. Saini H, Chhibber S, Harjai K. Azithromycin and ciprofloxacin: a possible synergistic combination against Pseudomonas aeruginosa biofilm-associated urinary tract infections. Int J Antimicrob Agents. 2015;45:359-67.

28. McMullan BJ, Mostaghim M. Prescribing azithromycin. Aust Prescr. 2015;38:87-9.

\section{Ready to submit your research? Choose BMC and benefit from:}

- fast, convenient online submission

- thorough peer review by experienced researchers in your field

- rapid publication on acceptance

- support for research data, including large and complex data types

- gold Open Access which fosters wider collaboration and increased citations - maximum visibility for your research: over $100 \mathrm{M}$ website views per year 